\title{
Subjectivity on career bamier of female college students majoring sport studies
}

\author{
Wangsung Myung ${ }^{1}$ \& Eunah Hong ${ }^{2 *}$ \\ ${ }^{1}$ Yonsei University \& ${ }^{2}$ Ewha Womans University
}

\begin{abstract}
[Purpose] The purpose of this study was to conduct a typological classification of female college students in sport studies regarding perceived career barriers. [Methods] Q-methodology was used to identify female college students' viewpoints on carrier barriers. The $\mathrm{Q}$ sample was distilled from 76 statements (64 from literature reviews and 12 in-depth interviews) to 25 statement after conducting literature review, in-depth interviews and surveys with open-ended questions. The P sample for this study was 30 students around Seoul and PQmethod software was used for data analysis. [Results] Three distinct views were extracted: First type of 'career opaque', revealed that students have failed to find their own aptitude and interest. Second type of 'sexual discrimination-male centered', implied students' concerns about discriminating factors in relation to marriage and pregnancy for the job they desire. Third type of 'Insufficient experience and qualification', indicates students perceive their lack of experience or qualification required for their career. [Conclusions] The identification of these three viewpoints could provide insights that can be used to design more segmented and detailed career policies for female college students in sport studies.
\end{abstract}

Key words: Sport studies, Female college students, Career barrier, Subjectivity, Q methodology

\section{서 론}

유리천장(Glass ceiling)이라는 말이 있다. 1970년대 미국에서 여성들의 취업과 승진을 가로막는 사회 편견 및 직장 조직의 태도를 묘사하기 위해 사용된 용어이다 (Wrigley, 2002). Morrison, White \& Van Velsor (1987)는 여성들이 사회에서 합당한 지위를 획득하는 데 방해되는 장애물을 유리천장으로 정의하였으며, 이를 남 녀 간 존재하는 심각한 불평등 중 하나로 규정하였다. 이 러한 유리천장 현상은 국내 사례를 통해서도 어렵지 않게 발견할 수 있으며, 단순히 승진 장벽뿐만 아니라 왜곡된

논문 투고일 : 2020. 03. 09.

논문 수정일 : 2020. 04. 27.

게재 확정일 : 2020. 05. 12.

*교신저자 : 홍은아(unahong@ewha.ac.kr).
젠더 역할, 직무 제한, 채용 과정 및 임금 수준 등으로 그 논의가 확장되고 있다(Hong, 2004; Kim, 2018; Lee, Han, Sung \& In, 2007; Min, 2012).

이렇듯 유리천장에 대한 국내 학계의 문제의식은 여성 들의 취업, 승진, 직무환경에서의 불평등 요인을 규명하 는데 많은 지적 관심과 활동으로 이어졌다. 그리고 다양 한 사회 지표들은 실제 한국사회에서 여러 유형의 유리천 장이 존재하고 있음을 방증한다. Organization for Economic Cooperation and Development(2017)의 보 고에 따르면, $\mathrm{OECD}$ 가입국 여성인력의 평균 경제활동참 여율은 $83.9 \%$, 고용률은 $79.5 \%$ 로 우리나라와 비교했을 때 각각 $18.9 \%, 16.7 \%$ 높은 수준을 보이고 있다. 또한 영국 경제주관지 Economist(2019, Mar. 8)는 각종 사 회 지표에 근거하여 $\mathrm{OECD}$ 회원국의 유리천장 지수를 발 
표했는데, 우리나라는 29 개 국가 가운데 최하위에 위치 하였다. 이는 여성 고용, 남녀 임금격차, 여성 임원, 여성 정치인, 고등교육 등 양성평등 수준을 종합하여 점수화한 결과이다. 더욱 아쉬운 점은 최근 7년 동안 최하위 수준 을 벗어나지 못하고 있다는 데 있다.

이러한 유리천장 현상은 국내 스포츠 분야에서도 예외 가 아니다. 한편으로는 여느 분야보다 양성평등 문제가 더욱 심각해 보인다. 체육회 통합 이전인 2014년 자료에 따르면, 대한체육회 및 17 개 시도체육회의 조직 구성원 451명 중 여성 근로자 수는 95명 (21\%)으로 남성 비율 (79\%)과 상당한 차이를 보이고 있다(Park, 2014). 같은 자료에서 보고된 국민생활체육회 및 17 개 시도생활체육 회의 여성 근로자 수는 246 명 중 47 명 (19.1\%)이다. 이 는 같은 기간 우리나라 전체 여성 고용률 $49.7 \%$ 보다 현 저히 낮은 수치이며(KOSIS, 2014), 남녀 간 고용률의 불균형이 스포츠 분야에서 더욱 두드러짐을 보여준다. 그 리고 2019년 6월 기준 통합체육회 임원진(회장, 부회장, 사무총장, 이사 등)은 총 46명으로 구성되어 있는데 그중 여성은 6명 (13\%)에 불과하다(대한체육회 홈페이지 참 고). 이뿐만 아니라 체육지도자 역시 전체 1 만 9,374 명 중 여성 지도자는 3,444명 (17.7\%)에 불과하며(대한체 육회 스포츠지원포털 참고), 일각에서는 체육계 미투의 구조적 원인 중 하나로 남녀 지도자 수의 불균형을 지적 하였다(Jo \& Lee, 2019, Jan. 12; Lee, 2019, Jan. 17).

이처럼 유리천장 현상은 우리사회 전반에 걸쳐 기취업 여성의 승진부터 고용, 임금, 교육, 정·재계 인사까지 다 양한 요인에 의해 더욱 심화되고 있다. 그중 본 연구에서 는 여성 미취업자들이 지각하는 '진로장벽(career barrier)' 요인에 주목하고자 한다. 진로장벽 요인은 승 진, 임금, 업무분담의 차별 등 기취업자들이 겪는 유리천 장과 달리, 진로를 탐색 및 준비하는 과정에서 경험하는 성 차별 및 불평등에 초점을 두고 있다. 일반적으로 진로 장벽 요인은 여성의 취업을 방해하거나 가로막는 내적 및 외적 장벽으로 통용된다(Shon, 2001a). 그리고 진로장 벽에 관한 연구들은 요인 특성상 여자 청소년과 대학생, 즉 미취업 여성을 주요 대상으로 선정하여 그들의 취업준 비 및 고용과정에서의 고충을 탐구해왔다 $\mathrm{Kim} \&$ Choi, 2014; Lee \& Jyung, 2007; Lee \& Yu, 2009; Lem \&
An, 2016; Lim \& Chang, 2015; Park, Shin \& Choi, 2010; Ryu \& Jeong, 2016; Shon, 2001a, 2001b).

그중 여자 대학생을 대상으로 한 연구들을 살펴봄으로 써 미취업 여성의 진로장벽 요인을 다양한 측면에서 이해 하고자 한다. 국내에서 처음으로 여자 대학생의 진로장벽 검사 도구를 개발한 Shon(2001a)은 차별, 직장생활에 필요한 개인적 특성의 부족, 다중 역할로 인한 갈등, 미결 정 및 직업준비 부족, 노동시장 및 관습의 제약, 기대보다 낮은 직업 전망, 여성 취업에 대한 고정관념 등 7개 요인 을 도출하였다. Lem \& An(2016)은 질적 자료를 통해 여대생의 '여성으로서 일의 의미'를 탐색하였으며, 내적 진로장벽으로 다중역할의 부담, 낮은 자기효능감, 비전 통적 진로선택의 어려움, 여성성에 대한 부정을, 외적 진 로장벽으로 학교 밖의 일상화된 성차별, 안정성 신화에 가려진 성별화된 직종 남녀공학, 여전히 존재하는 아들선 호, 대학에서 관습화된 성차별 문화를 범주화하였다. 이 두 연구에서 도출된 여자 대학생의 진로장벽 요인은 젠더 문제가 지니고 있는 장벽뿐만 아니라 직업적 자질, 자기 효능감, 진로준비 및 결정행동, 노동시장 등과 같은 개인 및 사회구조적 특성을 포함하고 있다.

Ryu \& Jeong(2016)는 이공계 여대생들의 진로장벽 이 진로타협 유형에 따라 다르게 나타고 있음을 발견하였 다. 구체적으로 이상지향형은 직업정보 부족, 미래 불안 을, 수입지향형은 자기명확성 부족, 경제적 어려움, 흥미 부족을, 일-가정균형지향형은 중요한 타인과의 갈등을 진로장벽으로 높게 인식하였으며, 반면에 일지향형은 진 로장벽 인식 수준이 전반적으로 낮았다(Ryu \& Jeong, 2016). 한편, Park \& Ahn(2016)은 여대생의 진로장벽 에만 초점을 둔 연구들과 달리, 남자 대학생과의 차이를 검증하였다. 구체적으로 자기명확성 부족, 대인관계 어 려움, 경제적 어려움, 타인과의 갈등, 직업정보 부족, 나 이문제, 신체적 열등감, 흥미부족, 미래불안 총 9 개 하위 요인 중 자기명확성과 대인관계에서 여학생의 어려움이 상대적으로 높게 나타났다. 이 두 연구는 변수 간 관계에 초점을 둔 전통 방법론과 달리, 진로에 대한 개인적 가치 와 성별에 따른 진로장벽의 차이를 규명했다는 점에서 의 미가 있다.

그러나 위 연구 사례들과 달리 스포츠 분야에서는 진 로장벽과 관련된 학계의 문제의식과 그 지적 관심이 상대 
적으로 소외되어왔다. 몇몇 체육학 연구자들 (Kim, Kim, Choi, Park \& Eom, 2011; Lee, 2016; Ryu, Park \& $\mathrm{Kim}, 2014)$ 에 의해 체육계열 학부생의 진로 관련 연구 가 수행되어지긴 했으나 이들 연구는 남녀 간 차이 또는 여성의 진로장벽에 주목하기 보다는 연구 대상자들을 체 육계열 대학생이라는 범주에 통합하여 접근하였다. Lee(2016)는 성별이 아닌 학년별 취업준비 인식현황과 개선방안을 탐색하였고, Ryu et al. (2014)는 개인적 특 성에 따른 진로장벽보다는 변수 간 관계(모형)를 검증하 는데 초점을 두었다. Kim et al. (2011)는 체육계열 학부 생을 위한 진로장벽 척도개발 및 타당성 연구를 진행했으 나 연구 대상으로서 여성 비율은 $29 \%$ 에 불과했다.

앞서 살펴본 바와 같이, 본 연구는 스포츠 분야에서의 유리천장(특히, 미취업 여성들의 진로장벽)과 그에 따른 남녀 고용률의 불균형이라는 문제의식으로부터 출발하 였다. 남성중심의 노동시장, 여성에 대한 사회적 편견 및 다중역할 요구 등 사회구조적 특성(Lee \& Jyung, 2007)과 최근 임시직 및 일용직의 증가와 같은 노동시장 의 질적 변화 $(\mathrm{Lim} \&$ Chang, 2015)는 여성의 진로발달 을 저해하고 있어 이에 대한 학술적 검토가 요구되는 실 정이다. 더욱이 여성이 지각하는 진로장벽은 남성의 사회 문화적 맥락과 분리하여 접근할 필요가 있음에도 체육계 열 여자 대학생에 초점화된 연구는 학술주제로서 관심 받 지 못했다.

이에 본 연구는 체육계열 여자 대학생이 지각하는 진 로장벽을 심층적으로 탐색하고자 한다. 구체적으로 $\mathrm{Q}$ 방 법론을 분석 틀로 차용하여 체육계열 여자 대학생들의 진 로장벽에 관한 심리적 주관성과 수용인식을 유형화하는 데 그 목적이 있다. 이는 개인의 내부 관점에 의존한 것으 로 가설 검증(연역적 접근)보다는 가설 추론(발견)에 근 접한 접근 방식을 채택한 것이다(Kim, 2008). 체육계열 여자 대학생의 진로장벽에 관한 연구가 매우 부족하다는 점에서 "가설을 발견해가는 가설추론적 Q방법론 $(\mathrm{Kim}$, 2008:13)"은 본 연구 목적에 적합한 분석 틀을 제공한 다. 즉, 특정 대상에 대한 이론적 가설이 축적되지 않은 상황에서 변수 간 관계를 검증하기보다 관련 요인을 추론 해나가는 접근 방식이 적절하다고 판단하였다.

Q방법론은 Stephenson(1953)에 의해 처음 개발되었 으며, 국내에서는 $\operatorname{Kim}(1992,2008)$ 와 Korean Society for the Science Study of Subjectivity(2002, 2014)가 선도하고 있다. 주로 인간 심리와 행동을 연구 대상으로 하는 학문 분야(특히, 심리학, 사회학, 교육학, 간호학, 광고학 등)에서 활용되고 있다. Q방법론은 특정 현상(여 기서는 진로장벽에 관한 개인적 체험)을 참여자의 주관 성 구조로부터 파악하는 것으로 내재적 접근 방식을 취하 고 있다. 이는 연구자가 사전에 조작한 가설 모형을 검증 하는 연역적 접근과 달리, 참여자의 지각 판단에 의해 $\mathrm{Q}^{-}$ 표본(또는 $\mathrm{Q}$-진술문)을 조작하기 때문에 해석적이라고 할 수 있다. 이처럼은 $\mathrm{Q}$ 방법론은 기존의 전통 방법론에 서 상대적으로 과소평가되었던 심리적 주관성에 의미를 부여하게 해준다(Kim, 2008). 특히, Q방법론의 인간 대 상 연구에서의 실용성은 체육계열 여자 대학생들의 진로 장벽에 관한 수용인식이 어떻게 유형화되고 또 각 유형들 이 지닌 특징을 이해하는 데 도움이 될 것이다.

이러한 작업을 통해 진로장벽에 관한 체육계열 여자 대학생들의 심리적 주관성 유형을 구조화하고 각 유형별 특징을 파악할 수 있을 것으로 기대한다. 궁극적으로 참 여자들의 개인적 특성과 진로유형에 따른 진로장벽 수용 인식은 학계에 유의미한 학술적 논의를 제공할 뿐만 아니 라 정책 결정에 필요한 실천적 논의를 제공할 수 있을 것 이다. 더 나아가 변수 간 관계 검증에 초점을 둔 다수의 진로장벽 연구들과 달리, 체육계열 여자 대학생의 내부 관점으로부터 진로장벽에 대한 수용인식을 규명함으로 써 전통 방법론의 한계점을 극복하고자 한다.

연구 목적을 달성하기 위한 세부적인 연구 문제는 다 음과 같다. 첫째, 체육계열 여자 대학생이 수용한 진로장 벽의 유형은 무엇인가(유형분석). 둘째, 각 유형별 특징 은 무엇인가(유형해석). 셋째, 유형별 학술적 또는 실천 적 의의는 무엇인가(논의).

\section{연구방법}

본 연구는 체육계열 여자 대학생들의 진로장벽에 관한 심리적 주관성과 수용인식을 유형화하는데 그 목적이 있 으며, 이를 위해 $\mathrm{Q}$ 방법론을 분석 틀로 차용하였다. Mckweon \& Thomas(2013)에 따르면, Q방법론은 참여 자의 자아구조를 정량적으로 유형화하는데 적합한 연구 
방법으로 양적 및 질적 접근의 속성을 함께 지니고 있다. 그럼에도 불구하고 $\mathrm{Q}$ 방법론이 질적 연구로 분류되는 결 정적 이유는 연구자의 역할이 분석도구로서 중요한 위치 를 점하고 있기 때문이다. 실제로 $\mathrm{Q}$ 방법론의 수행 절차 는 $\mathrm{Q}$-표본, $\mathrm{P}$-표본, $\mathrm{Q}$-분류, $\mathrm{Q}$-요인분석 총 네 단계로 구성되는데, 이중 마지막 단계인 Q-요인분석의 일부(소 프트웨어 패키지 사용)를 제외한 모든 과정에서 연구자 의 판단과 개입이 불가피하다. 본 연구 역시 위의 네 가지 단계를 거쳐 자료수집과 분석이 이루어졌으며, 이에 관한 상세한 내용은 다음과 같다.

\section{Q-표본(Q-sample 또는 Q-statement)}

본 연구는 $\mathrm{Q}$-표본을 추출하기 위한 초기 단계로서 $\mathrm{Q}^{-}$ 모집단(Q-population)을 구성하였다. Q-모집단 구성은 '여자 대학생', '체육계열', '진로장벽'과 관련된 문헌(주로 척도개발 연구) 고찰과 심층면담, 개방형 질문지 등 다각 적 자료수집방법을 활용하였으며, 이는 Watts \& Stenner(2005)가 제시한 구조화된 Q-표본과 비구조화 된 $\mathrm{Q}$-표본을 병행한 것이다. 여기서 구조화된 $\mathrm{Q}$-표본은 양적 배경으로부터 $\mathrm{Q}$ 에 접근하는 연구자들에게 호소력 을 지닌 반면, 연구 대상의 대표성과 포괄성, 사회문화적 맥락에 관한 문제(issue)는 비구조화된 $\mathrm{Q}$ 표본으로 보완 할 수 있다(Watts \& Stenner, 2005).

먼저 여자 대학생들의 진로장벽 요인을 유형화한 Shon(2001a)의 연구를 Q-모집단 구성에 활용하였다. Shon(2001a)은 그동안 여성들의 진로장벽을 포괄적으 로 파악 및 분류하였던 선행연구들의 한계점을 극복한 사 례로서 성, 인종, 민족(문화)에 따른 진로장벽의 차이에 초점을 두었다. 무엇보다도 국내 여자 대학생들을 위한 진로장벽 측정도구를 개발하였기 때문에 본 연구 주제에 적합하다. 이는 국내 사회문화적 맥락을 반영한 것으로 여자 대학생들이 지각하는 진로장벽을 파악하는데 유용 하다. 본 연구에서 $\mathrm{Q}$-모집단으로 차용한 요인은 차별, 직 장생활에 필요한 개인적 특성의 부족, 다중 역할로 인한 갈등, 미결정 및 직업준비 부족, 노동시장 및 관습의 제 약, 기대보다 낮은 직업 전망, 여성 취업에 대한 고정관념 등 총 7 개 요인이다.

다음은 체육전공자들의 진로장벽검사도구를 개발한
Kim et al.(2011)의 연구를 참고하였다. 앞서 언급한 Shon(2001a)이 전공을 구분하지 않고 국내 여자 대학생 에 초점화된 연구를 수행하였다면, Kim et al.(2011)의 연구는 체육계열에 제한을 두었다는 점에서 본 연구의 목 적과 유사하다. 본 연구에서는 대인관계의 어려움, 다중 역할 갈등, 경제적 어려움, 중요한 타인과의 갈등, 직업정 보 부족, 주위의 기대, 사회인식 문제, 흥미적성 부족, 전 문적 소양 부족 등 총 9 개 요인을 Q-모집단에 포함시켰다.

마지막으로 체육계열 여자 대학생 10 명을 대상으로 심 층면담을 실시하였으며, 이를 통해 선행연구에서 관찰되 지 않은 진로장벽을 귀납적으로 분석하였다. 심층면담은 반구조화된 면담으로서 개인당 최소 30 분에서 최대 60 분 진행하였다. 공통 질문은 자신의 전공에 대한 전반적 견 해(선택 이유, 만족감, 전망 등), 희망 직업, 취업준비행 동(또는 취업준비행동을 못하는 이유), 취업 준비 시 어 려움, 진로를 위한 개선방안 등을 활용하였다. 면담자료 는 주제 분석(thematic analysis)을 활용하여 진로장벽 과 관련 있는 주제를 범주화하였다. 심층면담을 통해 직 업탐색, 직업인식, 직업정보, 전공지식, 전공연계, 성 차 별 등 총 6 개 요인을 $\mathrm{Q}$-모집단에 추가하였다.

이러한 일련의 과정을 거쳐 총 76 개 (문헌 $=64$ 개, 심층 면담 $=12$ 개 $)$ 의 진술문을 1 차 Q-모집단으로 확보하였다. 이후 중복되거나 내용 타당성에 오류가 의심되는 진술문 을 통합 및 제외하였다. 추가로 전문가 집단의 동료검증 을 통해 연구 목적과 대상에 적합하지 않은 진술문을 제 거하였으며, 최종적으로 25 개의 $\mathrm{Q}$-표본을 추출하였다. $\mathrm{Q}$-표본에 관한 자세한 내용은 〈Table 1>과 같다.

\section{$\mathrm{P}$-표본(P-sample 또는 Q-sorter)}

진로장벽은 진로를 결정한 집단보다 그렇지 않은 집단 에서 더욱 두드러지게 지각하고 있다(Shon, 2001b). 이 에 본 연구는 P-표본 선정에 있어 진로결정집단과 진로 미결정집단의 균형 있는 분포를 고려하였으며, 이를 통해 연구 결과의 편향성을 유의하였다. 추가로 대학 졸업을 앞둔 고학년(3-4학년) 집단을 선정 기준에 반영하였으 며, 이는 고학년 집단이 저학년(1-2학년) 집단보다 진로 에 대한 관심이 더 크다고 판단했기 때문이다.

이러한 유의사항을 고려하여 수도권 4년제 대학에 재 
Table 1. Q-statement

\begin{tabular}{|c|c|}
\hline No. & Q-statement \\
\hline 1 & My network for getting a job is limited. \\
\hline 2 & Working conditions for the desired-job is poor. \\
\hline 3 & Marriage interferes with getting a job and promotion. \\
\hline 4 & The job I desire is not suitable for women. \\
\hline 5 & $\begin{array}{l}\text { Financial resource is required when preparing job } \\
\text { application. }\end{array}$ \\
\hline 6 & The job I desire is not recognized properly in society. \\
\hline 7 & There are limited professions associated with my major. \\
\hline 8 & People around me do not support my career. \\
\hline 9 & $\begin{array}{l}\text { I do not have much knowledge about the profession and } \\
\text { prospect in the field of sport. }\end{array}$ \\
\hline 10 & My major is an obstacle for me to get a job. \\
\hline 11 & $\begin{array}{l}\text { The working condition(salary, well-being) of my } \\
\text { desired-job is poor. }\end{array}$ \\
\hline 12 & $\begin{array}{l}\text { The job(organization) I desire is male-centered in hiring } \\
\text { and promoting staff. }\end{array}$ \\
\hline 13 & I do not know which job suits my aptitude and ability. \\
\hline 14 & The job I desire and my major do not match. \\
\hline 15 & There is a lack of supporting information for job search. \\
\hline 16 & Gender stereotypes remain in the job I desire. \\
\hline 17 & I have to choose a career that is not related to my aptitude. \\
\hline 18 & Childbirth interferes with getting a job and promotion. \\
\hline 19 & I do not have enough qualifications. \\
\hline 20 & The desired-job-outlook is not good. \\
\hline 21 & My family does not support my career path. \\
\hline 22 & I do not know what I like. \\
\hline 23 & $\begin{array}{l}\text { My physical condition or appearance are not suitable for } \\
\text { the job I desire. }\end{array}$ \\
\hline 24 & My field experience relating to career is not sufficient. \\
\hline 25 & $\begin{array}{l}\text { I am concerned about the relationship with colleagues in } \\
\text { the future. }\end{array}$ \\
\hline
\end{tabular}

학 중인 체 육계열 여자 대학생 33 명을 1 차적으로 선정하 였다. 이중 $\mathrm{Q}-$ 분류과정에서의 기재오류, 단순응답으로 인한 신뢰도 문제 등이 발견된 3 명을 제외하였으며, 최종 적으로 30 명의 $\mathrm{P}$-표본을 분석에 활용하였다. $\mathrm{P}$-표본에 대한 개인적 특성은 요인분석 결과와 함께〈Table 4〉에 제시하였다.

\section{$\mathrm{Q}$-분류( $\mathrm{Q}$-sort)}

$\mathrm{Q}$-분류는 선정된 $\mathrm{P}$-표본(응답자)이 $\mathrm{Q}$-표본을 정규분 포도에 강제 분류하는 과정으로 $\mathrm{Q}-$ 요인분석을 위한 사전 작업이다. 먼저 본 연구자는 응답자에게 25 개의 $\mathrm{Q}$-표본 카드를 제공한 후 검토할 시간을 충분히 제공하였다. 이 후 정규분포형태로 고안된 $\mathrm{Q}$-분류차트에 $\mathrm{Q}$-표본 카드를 긍정, 부정, 중립 순으로 강제 분류할 것을 유도하였다. 예컨대, 응답자들은 진로장벽에 대한 수용인식 정도 $(-4$, $-3,-2,-1,0,+1,+2,+3,+4)$ 에 따라 $\mathrm{Q}$-표본 카드를 〈Figure 1〉에 제시한 $\mathrm{Q}$ 분류차트에 각각 분류하였다. 이 후 응답자들은 1 차로 완성된 $\mathrm{Q}-$ 분류차트에 대해 재검토 및 수정하는 시간을 가졌으며, 더 이상 수정사항이 없을 경우 $\mathrm{Q}$-분류를 종료하였다.

선정된 $\mathrm{P}$-표본으로부터 진로장벽 요인과 유의미한 관 계를 보이는 진로직업역량(Ha, Kim, Kang, \& Cha, 2017; Park \& Ahn, 2016) 및 진로준비행동(Chang, Lee \& Sin, 2016; Kang, 2015; Kim, 2016; Kim \& Park, 2013; Park, 2018)을 추가로 조사하였다. 진로직업 역량은 희망 직업 또는 진로유형을, 진로준비행동은 취업 준비에 소비하는 시간, 비용, 방법 등을 통해 확인하였으며, 이는 요인 분석 시 유형별 해석에 유용한 정보를 제공하였다.

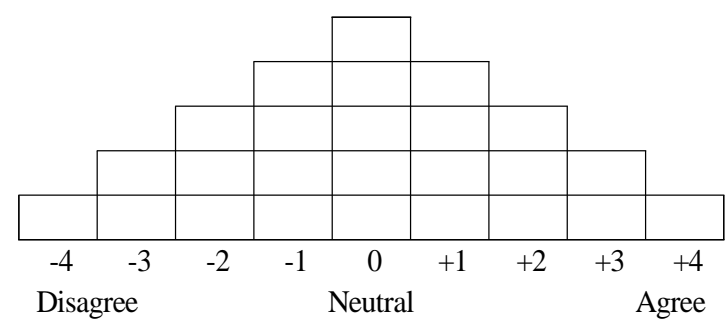

Fig. 1. Q-sort chart

\section{Q-요인분석(Q-analysis)}

Q-요인분석은 $\mathrm{P}-$ 표본의 심리적 주관성을 유형화하기 위한 단계이다. 일반적으로 $\mathrm{R}$ 방법론에서의 요인분석은 변수 간 관계성을 탐색 또는 확인하지만 $\mathrm{Q}$ 방법론은 개인 의 주관성 간 유사성에 초점을 둔다. 여기서 주관성이란 체육계열 여자 대학생의 진로장벽에 관한 수용인식을 의 미한다. 따라서 진로장벽에 관한 수용인식이 유사한 집단 은 하나의 요인으로 추출되며, 각 요인의 특성은 $\mathrm{Q}$ 표본 
의 표준점수(Z-score)와 응답자들의 개인적 특성을 통해 해석 및 명명할 수 있다. 추가로 요인 간 상관계수 및 $\mathrm{Q}^{-}$ 표본 표준점수의 유의미한 차이는 요인 간 비교 논의에 활용된다.

본 연구는 Q-요인분석을 위해 Q방법론 소프트웨어 패 키지 중 하나인 PQmethod(ver.2.35)를 활용하였다. 먼 저 PQmethod 프로그램에 새로운 프로젝트를 생성한 후 $\mathrm{Q}$ 표본과 $\mathrm{P}$-표본에 관한 정보를 코딩하였다. 이후 앞서 실시한 $\mathrm{Q}$-분류차트에 대한 코딩 작업을 진행하였다. 마 지막으로 직각회전방법 중 베리맥스(varimax)를 활용한 요인분석을 실시하였다. 분석 대상으로 채택한 요인들은 고유치 (eigenvalues) 1.0 이상으로 설정하였다.

\section{결과}

\section{유형 분석}

$\mathrm{Q}-$ 요인분석 결과, 체육계열 여자 대학생들의 진로장 벽에 관한 심리적 주관성은 세 가지 유형으로 관찰되었 다. 각 유형별 고유치를 살펴보면, 유형 I이 9.52로 가장 높게 나타났다. 이는 세 유형 중에서 유형 I이 상대적으로 중요한 요인임을 의미한다. 다음으로 유형 II가 3.99, 유 형 III은 3.08 으로 각각 나타났다. 각 유형이 전체에서 설 명하는 비율은 유형 I(20\%), 유형 II(20\%), 유형 $\operatorname{III}(15 \%)$ 순으로 나타났다.

Table 2. Eigenvalues and variation

\begin{tabular}{cccc}
\hline \hline Item & I & II & III \\
\hline Eigenvalues & 9.52 & 3.99 & 3.08 \\
\hline \% expl.Var. & 20 & 15 & 20 \\
\hline cum\% expl.Var. & 20 & 35 & 55 \\
\hline \hline
\end{tabular}

Table 3. Correlations between types

\begin{tabular}{cccc}
\hline \hline Type & I & II & III \\
\hline I & 1 & - & - \\
\hline II & .253 & 1 & - \\
\hline III & .469 & .281 & 1 \\
\hline \hline
\end{tabular}

추출된 유형들 간의 상관계수는 유형 I과 유형 III이 .469로 가장 높은 유사성을 보였다. 유형 I과 유형 II는 .253, 유형 II와 유형 III은 .281로 나타났다. 유형별 고 유치 및 변량은 〈Table 2 , 유형 간 상관계수는 〈Table 3)과 같다.

Q-요인분석 결과, 30 명의 P-sample 중 29명이 세 개 유형을 설명하는 것으로 나타났다. 구체적으로 11 명이 유형 I의 전형으로 나타났으며, 유형 II는 7명, 유형 III은 11 명으로 각각 분류되었다. 한편, 1 명은 두 개 이상의 유 형에서 교차적재 (cross loading)가 발견되었다. 각 유형 별 $\mathrm{P}$-표본의 분포 및 요인적재량 그리고 개인적 특성은 〈Table 4〉와 같다.

\section{유형 해석}

유형 해석은 앞서 추출된 세 개 유형을 연구자가 해석 및 명명하는 단계이다. 통상적으로 $\mathrm{Q}$ 방법론에서의 유형 분석은 소프트웨어 패키지 (본 연구에서는 $\mathrm{PQmethod)}$ 를 통해 검증하고, 유형 해석은 연구자 및 전문가 집단의 역 할이다. 본 연구는 각 유형별 표준점수(Z-score) \pm 1.0 이 상인 $\mathrm{Q}$ 표본을 바탕으로 각 유형의 특징과 유형 간 차이 점 및 유사성을 파악하였다. 추가로 각 유형에 분류된 $\mathrm{P}-$ 표본의 개인적 특성과 유형 간 상관계수를 유형 해석 시 활용하였다. 이러한 절차를 통해 유형 I은 '진로 불확실 형', 유형 II는 ‘성차별-남성중심형', 유형 III은 ‘경험-자격 부족형'으로 각각 명명하였다.

\section{유형 | : 진로 불확실형}

유형 I은 고유치 9.52 로 연구의 총 설명변량 중 $20 \%$ 를 설명하였으며, 11 명의 응답자가 통계적으로 유의미한 상 관성을 보였다. 표준점수가 \pm 1.0 이상인, 즉 강한 긍정과 부정을 나타내는 $\mathrm{Q}$-표본은 총 7 개 (긍정 $=2$, 부정 $=5$ )로 나타났다. 여기서 강한 긍정이란 표준점수가 높은 Q-표 본을 가리키며, 이는 해당 유형에서 높은 진로장벽임을 의미한다. 이와 달리 강한 부정, 즉 표준점수가 낮은 $\mathrm{Q}^{-}$ 표본일수록 해당 유형에서 낮은 진로장벽으로 이해할 수 있다.

유형 I은 '나의 적성(능력)에 맞는 직업을 잘 모르겠다 $(\mathrm{Z}=2.092)^{\prime}$ 를 가장 긍정적으로 수용하였으며, 다음으로 
Table 4. P-sample distribution by type and factor loading

\begin{tabular}{|c|c|c|c|c|c|c|}
\hline Type & ID & Desired job & $\begin{array}{l}\text { Time for preparation } \\
\text { (Daily) }\end{array}$ & $\begin{array}{l}\text { Cost for preparation } \\
\text { (Monthly, Thousand won) }\end{array}$ & Means & $\begin{array}{l}\text { Factor } \\
\text { loading }\end{array}$ \\
\hline \multirow{11}{*}{$\begin{array}{c}\mathrm{I} \\
(\mathrm{N}=11)\end{array}$} & 9 & Administrator & $\mathrm{n} / \mathrm{a}$ & $\mathrm{n} / \mathrm{a}$ & $\mathrm{n} / \mathrm{a}$ & .686 \\
\hline & 10 & $\mathrm{n} / \mathrm{a}$ & $\mathrm{n} / \mathrm{a}$ & $\mathrm{n} / \mathrm{a}$ & $\mathrm{n} / \mathrm{a}$ & .800 \\
\hline & 14 & Office worker & $2 \mathrm{hrs}$ & $10-100$ & Self study & .491 \\
\hline & 15 & Sport analyst & 5hrs or more & $210-300$ & Institution & .578 \\
\hline & 18 & Trainer & 5hrs or more & more than 300 & Certificate & .551 \\
\hline & 20 & Rehabilitation & 1hrs & $110-200$ & Internet & .562 \\
\hline & 21 & Researcher & 5hrs or more & $10-100$ & Internet & .576 \\
\hline & 23 & Business & $\mathrm{n} / \mathrm{a}$ & $\mathrm{n} / \mathrm{a}$ & $\mathrm{n} / \mathrm{a}$ & .758 \\
\hline & 24 & Business & $\mathrm{n} / \mathrm{a}$ & $\mathrm{n} / \mathrm{a}$ & $\mathrm{n} / \mathrm{a}$ & .630 \\
\hline & 27 & Paramedic & 3hrs & $10-100$ & Certificate & .623 \\
\hline & 30 & Start-up & 1hrs & $110-200$ & Institution & .618 \\
\hline \multirow{7}{*}{$\underset{(\mathrm{N}=7)}{\Pi}$} & 2 & Public official & 1hrs & $\mathrm{n} / \mathrm{a}$ & Self study & .572 \\
\hline & 3 & Soldier & 5hrs or more & $\mathrm{n} / \mathrm{a}$ & ROTC & .661 \\
\hline & 6 & Guard & $\mathrm{n} / \mathrm{a}$ & $\mathrm{n} / \mathrm{a}$ & Certificate & .670 \\
\hline & 7 & Coach & 3hrs & $110-200$ & Internet & .699 \\
\hline & 12 & Educator & $\mathrm{n} / \mathrm{a}$ & $\mathrm{n} / \mathrm{a}$ & $\mathrm{n} / \mathrm{a}$ & .699 \\
\hline & 19 & Trainer & 5hrs or more & $110-200$ & Certificate & .698 \\
\hline & 22 & PE Teacher & 2hrs & $\mathrm{n} / \mathrm{a}$ & $\mathrm{n} / \mathrm{a}$ & .622 \\
\hline \multirow{11}{*}{$\underset{(\mathrm{N}=11)}{\mathrm{II}}$} & 1 & Professor & 1hrs & $10-100$ & Certificate & .580 \\
\hline & 4 & $\mathrm{n} / \mathrm{a}$ & $\mathrm{n} / \mathrm{a}$ & $\mathrm{n} / \mathrm{a}$ & Internet & .656 \\
\hline & 5 & Sport apparel & 1hrs & $\mathrm{n} / \mathrm{a}$ & Study group & .745 \\
\hline & 8 & Announcer & 5hrs or more & more than 300 & Institution & .802 \\
\hline & 11 & Soldier & 5hrs or more & $\mathrm{n} / \mathrm{a}$ & ROTC & .737 \\
\hline & 13 & PE Teacher & - & $\mathrm{n} / \mathrm{a}$ & $\mathrm{n} / \mathrm{a}$ & .428 \\
\hline & 17 & Soldier & 1hrs & $\mathrm{n} / \mathrm{a}$ & ROTC & .618 \\
\hline & 25 & Announcer & $\mathrm{n} / \mathrm{a}$ & $\mathrm{n} / \mathrm{a}$ & $\mathrm{n} / \mathrm{a}$ & .584 \\
\hline & 26 & $\mathrm{n} / \mathrm{a}$ & $\mathrm{n} / \mathrm{a}$ & $110-200$ & Certificate & .497 \\
\hline & 28 & Public official & 4hrs & $210-300$ & Self study & .721 \\
\hline & 29 & Sport marketer & $\mathrm{n} / \mathrm{a}$ & $\mathrm{n} / \mathrm{a}$ & $\mathrm{n} / \mathrm{a}$ & .637 \\
\hline Invalidity & 16 & $\mathrm{n} / \mathrm{a}$ & $\mathrm{n} / \mathrm{a}$ & $\mathrm{n} / \mathrm{a}$ & $\mathrm{n} / \mathrm{a}$ & - \\
\hline
\end{tabular}

'내가 좋아하는 일을 잘 모르겠다 $(\mathrm{Z}=1.655)$ 로 나타났다. 반면에 '나의 신체 조건이나 외모가 희망 직업과 어울리지 않다 $(\mathrm{Z}=-1.564)$ '를 가장 부정적으로 수용하였으며, '향 후 직장상사 및 동료와의 관계가 걱정된다 $(\mathrm{Z}=-1.503)^{\prime}$, '가족이 내 진로에 대해 반대한다 $(\mathrm{Z}=-1.403)$ ', '나의 적성 과 상관없는 직업을 선택해야 한다 $(\mathrm{Z}=-1.308)$ ', '지인들 이 내 진로를 지지해주지 않는다( $\mathrm{Z}=-1.169)^{\prime}$ 순이다.
긍정적 수용 인식의 주요 핵심어는 적성 미발견, 흥미 미발견, 직업정보부족 등이며, 부정적 수용 인식은 신체 조건, 대인관계, 사회적 지지, 적성 불일치 등이다. 이를 종합해볼 때, 유형 I은 진로장벽을 개인 외부로부터 수용 하기보다 자신의 적성 및 흥미와 같은 개인 내부로부터 수용하는 유형으로서 '진로 불확실형'으로 명명할 수 있다. 유형 I의 주요 Q-표본 및 표준점수는 〈Table 5 )와 같다. 
Table 5. Principle Q-sample and Z-score on Type ।

\begin{tabular}{clr}
\hline \hline No. & \multicolumn{1}{c}{ Q-sample } & Z-score \\
\hline 13 & I do not know the job that fits my aptitude. & 2.092 \\
\hline 22 & I do not know what I like. & 1.655 \\
\hline \hline 8 & People around me do not support my career. & -1.169 \\
\hline 17 & $\begin{array}{l}\text { I have to choose a career that is not related to } \\
\text { my aptitude. }\end{array}$ & -1.308 \\
\hline 21 & My family is against my career. & -1.403 \\
\hline 25 & I worry about the relationship with colleagues. & -1.503 \\
\hline 23 & $\begin{array}{l}\text { My physical condition or appearance is not } \\
\text { suitable for the job I wish. }\end{array}$ & -1.564 \\
\hline \hline
\end{tabular}

\section{유형 II: 성차별-남성중심형}

유형 II는 고유치 3.99로 총 변량의 $15 \%$ 를 설명하였 으며, 7 명의 응답자가 통계적으로 유의미한 상관성을 나 타냈다. 표준점수가 \pm 1.0 이상인 $\mathrm{Q}$ 표본은 총 7 개(긍정 $=4$, 부정 $=3$ )로 나타났다. 유형 II는 '출산은 취업과 승 진에 방해가 된다 $(\mathrm{Z}=1.715)^{\prime}$ 를 가장 긍정적으로 수용하 였으며, '희망 직업은 취업과 승진이 남성 중심적이다 $(\mathrm{Z}=1.690)$ ', '결혼은 취업과 승진에 방해가 된다 $(\mathrm{Z}=1.504)$ ', '희망 직업의 처우(임금, 복지 등)가 열악하 다 $(\mathrm{Z}=1.110)^{\prime}$ 순이다. 반면에 '가족이 내 진로에 대해 반 대한다 $(\mathrm{Z}=-1.603)$ '를 가장 부정적으로 수용하였으며, '내가 좋아하는 일을 잘 모르겠다 $(\mathrm{Z}=-1.320)$ ', '나의 적 성 (능력)에 맞는 직업을 잘 모르겠다 $(\mathrm{Z}=-1.306)$ '순이다.

긍정적 수용 인식의 핵심어는 결혼, 출산, 남성중심, 열악한 처우이며, 부정적 수용은 가족지지, 적성 미발견, 흥미 미발견 등이다. 이를 종합해볼 때, 유형 II는 진로장 벽을 직장 내·외부에 존재하는 왜곡된 성 고정관념 및 성 역할로부터 수용하는 유형으로서 '성 차별-남성중심형'으 로 분류할 수 있다. 유형 II의 주요 Q-표본 및 표준점수는 〈Table 6〉와 같다.

\section{유형II: 경험-자격부족형}

유형 III은 고유치 3.08 로 총 변량의 $20 \%$ 를 설명하였 으며, 11 명의 응답자가 통계적으로 유의미한 상관성을 보이고 있다. 표준점수가 \pm 1.0 이상인 $\mathrm{Q}$-표본은 총 6 개
Table 6. Principle Q-sample and Z-score on Type II

\begin{tabular}{clc}
\hline \hline No. & \multicolumn{1}{c}{ Q-sample } & Z-score \\
\hline 18 & $\begin{array}{l}\text { Childbirth interferes with employment and } \\
\text { promotion. }\end{array}$ & 1.715 \\
\hline 12 & $\begin{array}{l}\text { Employment and promotion are male-centered } \\
\text { in the job. }\end{array}$ & 1.690 \\
\hline 3 & $\begin{array}{l}\text { Marriage interferes with employment and } \\
\text { promotion. }\end{array}$ & 1.504 \\
\hline 11 & The treatment of job I wish is poor. & 1.110 \\
\hline \hline 13 & I do not know the job that fits my aptitude. & -1.306 \\
\hline 22 & I do not know what I like. & -1.320 \\
\hline 21 & My family is against my career. & -1.603 \\
\hline \hline
\end{tabular}

(긍정 $=3$, 부정 $=3$ )로 나타났다. 유형 III의 응답자들은 '직업 관련 현장경험이 부족하다 $(\mathrm{Z}=2.022)$ '를 가장 긍정 적으로 수용하였으며, '취업에 필요한 자격요건(자격증, 공인영어점수, 경력 등)이 부족하다 $(\mathrm{Z}=1.762)$ ', '전공과 연계된 직업이 한정적이다 $(\mathrm{Z}=1.118)^{\prime}$ 순이다. 반면에 '가족이 내 진로에 대해 반대한다 $(\mathrm{Z}=-1.816)$ '를 가장 부 정적으로 수용하였으며, '지인들이 내 진로를 지지해주지 않는다 $(\mathrm{Z}=-1.699)$ ', '희망 직업이 사회에서 인정받지 못 한다 $(\mathrm{Z}=-1.525)^{\prime}$ 순이다.

긍정적 수용의 핵심어는 현장경험, 자격요건, 제한된 전공연계 등이며, 부정적 수용은 사회적 지지, 사회적 인 식 등이다. 이를 종합해볼 때, 유형 III은 진로장벽을 적 성 및 흥미와 같은 개인 내부에서 수용한 유형 I 과 달리, 교육 기회의 부재와 같은 외부로부터 수용하는 유형으로 서 '경험-자격부족형'으로 명명할 수 있다. 유형 III의 주요 $\mathrm{Q}$-표본 및 표준점수는 〈Table 7〉와 같다.

Table 7. Principle Q-sample and Z-score on Type III

\begin{tabular}{clr}
\hline \hline No. & \multicolumn{1}{c}{ Q-sample } & Z-score \\
\hline 24 & I have little experience with the job. & 2.022 \\
\hline 19 & I do not have enough qualifications. & 1.762 \\
\hline 7 & $\begin{array}{l}\text { There are limited professions associated with } \\
\text { major. }\end{array}$ & 1.118 \\
\hline \hline 6 & The job I wish is not recognized in society. & -1.525 \\
\hline 8 & People around me do not support my career. & -1.699 \\
\hline 21 & My family is against my career. & -1.816 \\
\hline \hline
\end{tabular}




\section{논의}

연구 결과, 진로장벽에 대한 체육계열 여자 대학생들 의 심리적 주관성은 세 유형으로 분류되었다. 각 유형은 '진로 불확실형'(유형 I), ‘성차별-남성중심형'(유형 II), '경험-자격부족형'(유형 III)으로 명명하였다. 이러한 결 과를 바탕으로 논의를 진행하고자 한다.

첫째, 유형 I은 '진로 불확실형'으로, 이 유형의 응답자 들은 자신이 무엇을 좋아하는지, 본인의 능력이나 적성에 어떠한 직업이 적합한지에 대한 확신이 없는 반면, 자신 의 신체조건 및 외모, 향후 직장에서의 인간관계 등은 진 로장벽으로 거의 수용하지 않았다.

교육부에서 처음으로 실시한 〈2017년 대학 진로교육 현황조사>에 따르면, 졸업 후 진로계획을 묻는 질문에 응 답자의 $22 \%$ 는 '아직 잘 모르겠다'고 답하였다(Ministry of Education, 2017, Dec. 14). Urbanaviciute, Pociute, Kairys \& Liniauskaite (2016)의 연구에 따르면 전공 에 대한 만족과 진로장벽은 매우 높은 관련성이 있는 것 으로 나타났는데 특히, 커리어 목표를 추구하는데 있어 자신의 능력, 흥미가 부족하다고 인식하는 내재적인 장벽 (internal barrier)이 전공 만족에 부정적인 영향을 미쳤 다. 이는 진로장벽을 개인 외부가 아닌 내부로부터 수용 하는 유형 I을 지지하는 결과이다.

여기서 주목할 점은 '여성'과 ‘체육계열 전공'이라는 두 가지 관점에서 유형 I로부터 얻을 수 있는 학술적 의의이 다. 다시 말해, 다른 전공계열의 학부생 및 일반 사회의 취업준비생도 진로에 대한 흥미 및 적성 부족이라는 고충 을 경험하고 있는데, 이를 체육계열 여자 대학생의 관점 에서 보다 깊은 논의가 필요하다는 것이다.

유형 I은 자신의 흥미, 능력, 적성 등에 대한 확신이 부 족한 것으로 '진로 결정'에 취약한 모습을 보이고 있다. Lent, Brown \& Hackett(2002)는 여자 대학생이 남학 생에 비해 진로 결정에 많은 고충을 겪고 있는데, 그 원인 으로 여성의 사회화와 직업 환경을 언급하였다. 이러한 주장은 여자 대학생 수의 증가에도 불구하고 여성 고급 인력의 수요는 현저히 낮아 여대생이 남성에 비해 진로 결정에 어려움을 겪고 있다는 Oh \& Lee(2005)의 연구 가 뒷받침한다. 이에 대해 일부 연구자들은 진로 결정에 부정적 영향을 미치는 여러 요인 중 '의사결정의존성'에
주목하였다(Mau, 1995; Phillips, Pazienza \& Walshi, 1984). 특히, 여성은 사회문화적 특성상 남성에 비해 높은 의사결정의존성을 보이고 있다는 점 (Mau, 2000)을 고려했을 때, 본 연구에서 발견한 유형 I의 진로 장벽과 같은 맥락에서 이해할 수 있다.

실제로 $\operatorname{Kim}(2009)$ 은 여자 대학생들의 의사결정의존 성이 진로결정에 부적 영향을 미치고 있음을 경험적으로 검증하였다. 이러한 관점에서 진로 불확실을 진로장벽으 로 강하게 수용한 유형 I은 의사결정의존성 측면에서 접 근 및 개선방안을 모색할 필요가 있다. 무엇보다 의사결 정의존성은 관계 또는 집단 지향적 문화에서 더욱 높게 형성된다는 점을 고려했을 때 (Kim, 2009), 위계적 집단 문화가 강하게 자리 잡은 국내 체육계(Nam, 2019; Nam \& Lee, 2019; Oh, 2017)에서 여성의 의사결정은 더욱 의존적일 수 있다.

고등교육(higher education)으로 진입한 대학생은 자 신이 선택한 전공에 대해 '현실 확인(reality check)'절차 를 밟으며 전공과 관련된 직업에 대해 알아보기 시작하는 데(Urbanaviciute et al., 2016), 이는 체육계열 여학생 들에게도 예외가 아니다. 따라서 고학년에 치우쳐 있는 대부분 대학교의 진로 관련 프로그램을 전면적으로 검토 하고, 신입생부터 맞춤형 진로 관리를 해 나가는 시스템 구축이 요구된다. 체육 관련 학과 교수진 및 진로상담 전 문가들은 인문사회, 이공계 학생들과 상이한 체육계 커리 어의 특징을 파악한 후 체육계열 여대생들이 진로에 관해 느끼는 장벽을 극복할 수 있도록 정서적, 실질적 지지를 보여줘야 할 것이며, 진로 관련 전공 세미나, 그룹 상담 프로그램 등의 개발도 고려할 수 있을 것이다 $(\mathrm{Kim} \&$ Yoon, 2016). 무엇보다 이러한 노력은 유형 I의 의사결 정의존성을 낮추고 궁극적으로 진로 결정을 저해하는 요 인을 해소하는데 초점을 두어야 할 것이다.

둘째, 유형 II는 '성차별-남성중심형'으로, 이 유형의 학생들은 결혼 및 출산이 취업이나 승진에 방해가 되고 희망 직업이 남성 중심적이라는 인식을 하는 것으로 나타 났다. Harris, Grappendorf, Aicher \& Veraldo(2015) 의 연구에서는 스포츠 경영 전공 여학생들이 전통적으로 남성 중심 영역인 스포츠 분야에서 일할 때 여성에 대한 고정관념을 경험할 수 있다는 것을 인지하고 있으며 특히 가정과 일의 양립, 네트워킹의 어려움, 낮은 급여와 긴 근 
무시간 등을 염려하고 있는 것을 밝혔다. Chuang(2010) 또한 여대생들이 직업을 찾는 과정에서 이주에 대한 거부 감, 어린 아이를 집에 두고 직장생활을 하는 부분에 대한 죄책감 등 가정과 관련된 장벽에 있어 남학생들에 비해 현저히 민감하게 인지하고 있다고 보고하였고, Watts, Frame, Moffett, Van Hein \& Hein(2015)는 여성이 남 성임원보다 여성임원이 드문 스포츠를 포함한 비전통적인 (non-traditional)분야로 진출하는데 망설일 가능성이 높다고 하였다. 이 연구들은 모두 유형 II를 지지하고 있다. 서론에서도 전술했듯이, 국내 체육계 양성평등 문제는 우리사회의 다른 영역과 해외 체육계보다 심각한 수준임 을 알 수 있는데 이러한 경향이 본 연구 결과에서도 발견 되었다. 이렇듯 유형 II는 개인 내부의 장벽으로 특징지어 진 유형 I과 달리, 사회구조적 장벽으로서 개인 외부에 존 재한다. 그리고 사회구조적 장벽의 특성상, 학계에서는 이 문제를 법제도적으로 접근하려는 시도가 지배적이었다.

스포츠지도자의 양성평등적 채용 방안을 연구한 $J_{00}$ (2010)는 미국 고용 관련 법률 및 정책을 근거로 국 내 스포츠계의 대응방안을 제시하였다. 그중 법제도적 방 안을 살펴보면, Title IX에서 명시하고 있는 '성비의 균형' 과 '적극적 우대조치’의 도입, 공개채용 의무화 및 내용의 명확성, 직무의 표준화 등 전반적인 채용 정책의 수정, 여 성 스포츠인의 인권 보호를 위한 전문 법률단 구성이 필 요하다고 하였다(Joo, 2010). Son(2015)은 체육계 양 성평등 실현을 위해서 국민체육진흥법(국민체육기본법 으로 개정), 교육기본법 및 기타 관련 법률, 대한체육회 제 규정의 개정이 불가피하다고 주장하였다.

$\operatorname{Kim} \& \mathrm{Seo}(2016)$ 는 여성 체육전문인력 고용 정책 요 인의 상대적 중요도와 우선순위를 분석하였는데, 체육조 직의 여성 중간 관리자 양성 제도가 최우선 순위로 나타 났다. 이 연구는 $\mathrm{AHP}$ 분석을 실시한 연구로서 여성 체육 전문가 집단 역시 체육계 여성 종사자들의 낮은 지위와 승진 장벽에 대해 높게 인식한 것으로 볼 수 있다. 또한, 성평등 세미나 제공은 가장 낮은 우선순위를 보였는데 (Kim \& Seo, 2016), 이는 개선방안과 같은 실질적 측면 에서 유의미한 시사점을 제공한다.

같은 맥락에서 유형 II의 진로장벽은 사회구조적 측면에 서 그 개선방안이 논의되어야 하며 특히, 법률의 제·개정 과 스포츠 조직의 고용 정책 및 인사 관리 제도의 개선이
무엇보다 중요한 과제이다. 여기에 본 연구 대상을 고려했 을 때, 전문가 집단(학계, 행정가, 정책결정자 등)으로 구 성된 학술 세미나뿐만 아니라 체육계열 여대생을 대상으로 스포츠 산업에서 종사하는 여성 실무자를 초청하여 특강, 토크쇼 등을 통한 상호작용의 기회를 확대할 필요가 있다. 이를 통해 여대생들에게 향후 스포츠 분야에서 경험할 수 있는 장벽들을 미리 파악 및 준비하고, 사실과 다른 왜곡된 정보를 분별할 수 있는 기회를 제공할 수 있을 것이다 (Chuang, 2010; Huang, Chou \& Hung, 2016).

셋째, 유형 III은 '경험-자격 부족형'으로, 이 유형의 학 생들은 희망 직업 관련 현장경험과 자격 요건 부족, 제한 된 전공연계 직업 등을 강하게 수용하였다. 잡코리아에서 조사한 〈2018 신입공채 취업준비 현황〉을 살펴보면, 취 업을 위해 준비하는 것에 대한 응답으로 '학점, 어학점수, 직무경험 강화'가 $36 \%$ 로 2 위 (1위는 전공분야의 전문지 식 강화, $43.4 \%$, 아르바이트, 비정규직 근무가 3 위 (35.4\%)로 나타났다(Won, 2018, Mar. 15). 최근 잡코 리아와 알바몬이 함께 실시한 설문조사에서는 4년제 대 졸자의 $42.3 \%$ 가 휴학 경험이 있고, $9.7 \%$ 가 졸업유예를 하였으며, 휴학과 졸업유예를 모두 경험한 학생이 $6.7 \%$ 를 기록했다. 휴학과 졸업유예의 이유로는 '인턴, 대외활 동, 아르바이트 등 취업에 필요한 사회, 직무 경험을 쌓기 위해‘ 라는 응답이 $30.4 \%$ 로 가장 높았다는 점(Moon, 2020, Feb. 10)은 직업 관련 경험, 현장경험 부족을 인 지하고 있는 유형 III을 뒷받침한다.

유형 III이 진로장벽으로 수용한 희망 직업에 대한 경 험 및 자격 요건 부족, 제한적 전공연계 직업은 '여성'으로 제한하기보다는 '체육계열 전공'의 측면에서 논의를 전개 할 필요가 있다. 이는 단순히 여대생에게만 해당되지 않 고 체육계열 전공자들이 전반적으로 겪는 고충이기 때문 이다. 체육계열 대학생의 진로 교육을 분석한 Lee, Lee, Yi \& Jin(2019)는 교육과정 내 진로교육 부족과 현장경 험지원의 미비를 문제점으로 도출하였다. 다른 연구에서 도 전공 교과과정에서의 진로교육의 미비, 비교과활동에 서의 진로교육의 전공 특수성 및 다양성 부족, 체육 진로 및 취업관련 실습환경 부족 등이 체육계열 대학생의 고충 으로 보고된 바 있다(Park \& Hong, 2016). 한편, 최근 연구에서는 체육계열 대학생의 불안정한 고용형태 (Shin, 2015), 취업직종의 확대 및 기회 제공(Lee, 
2016), 전공일치 직종에 대한 높은 선호(Lee, Yang \& Yoo, 2020)에 주목하기도 했다.

이들 연구의 특징은 남녀의 문제가 아닌 '체육계열 전 공의 교육과정'과 '노동 시장'의 구조적 문제로 바라보았 다는 점이다. 이러한 맥락에서 유형 III이 지각한 진로장 벽은 관련 학과 차원에서 진로교육에 관한 문제의식과 개 선 노력이 요구되어 진다. 따라서 체육 관련 학과 교수진 및 진로상담 전문가들은 전공 커리큘럼에 대한 심층적인 분석을 통해 스타트업 및 스포츠 유관기관들의 니즈에 맞 는 프로그램을 공동 개발·운영하면서 체육계열 여대생들 이 직무경험을 쌓을 수 있는 장(場)을 제공하여 진로장벽 을 낮추는 방안을 고민해야 할 것이다. 또한 '융합’이 화두 로 떠오른 이 시대에 체육 관련 전공은 수많은 타 영역과 '융합'할 수 있는 경쟁력 있는 전공이라는 점을 학생들에 게 주지시키는 노력도 필요할 것이다. 1 학년 때부터 접하 는 진로 관련 프로그램을 통해 자신의 적성, 흥미를 파악 하고 이를 바탕으로 복수전공, 부전공 제도를 적극 활용 하도록 독려한다면 체육계열 여대생들이 보다 넓은 시야 를 가지고 다양한 경험에 도전할 수 있을 것이다.

\section{결론 및 제언}

본 연구는 체육계열 여자 대학생의 진로장벽에 관한 심리적 주관성과 수용인식을 유형화하는 취지로 수행되 었으며 그 결과, 유형 I '진로 불확실형', 유형 II '성차별남성중심형', 유형 III '경험-자기부족형'으로 나타났다. 각 유형은 개인 내부(진로결정, 의사결정의존성)와 외부 (법제도적 측면, 대학의 교육과정)에 존재하는 장벽으로 특징지어졌으며, 이를 바탕으로 다양한 관점에서 학술적 및 실천적 논의를 제공하였다.

본 연구는 진로장벽과 관련된 변인의 인과관계를 규명 하고 매개, 조절 효과 등을 검증한 기존의 전통 방법론에 서 벗어나 $\mathrm{Q}$ 방법론을 활용하여 체육계열 여자 대학생의 주관적인 생각이나 태도를 유형화하여 분석했다는 점에 서 학술적인 의의를 찾을 수 있다. 또한 본 연구에서 도출 한 세 가지 유형에 대한 특징을 파악하고, 이를 바탕으로 보다 세분화된 체육계열 여대생의 진로교육 정책 수립의 필요성을 강조하였다는 점에서 실천적 의의를 주목할 수
있다. 그럼에도 불구하고 본 연구에서는 몇 가지 제한점 이 발견되었다.

첫째, 본 연구는 기존의 설문연구 규모보다 확연히 적 은 소규모 그룹 대상의 편의표집방식으로 $\mathrm{P}$ 표본을 구성 하였기에 $\mathrm{P}$ 표본의 대표성과 연구의 일반화에 한계가 있 다. 특히, 수도권 지역 체육계열 여대생으로 연구대상이 한정되었다는 점에서 후속 연구에서는 보다 폭넓은 $\mathrm{P}$ 표 본 선정이 이루어져야 할 것이다(Kim, 2018).

둘째, Q방법론은 요인 I, II, III에 속한 체육계열 여대 생의 비율을 바탕으로 전체 체육계열 여대생을 추론하는 것이 아니기에 본 연구의 결과로 도출된 세 유형 이외에 도 새로운 유형이 추가될 수 있는 가능성이 존재한다 (Cho, 2016). 후속 연구에서는 체육계열 여대생들의 진 로장벽에 관한 심리적 주관성을 보다 구체적으로 파악하 고 유형 모두를 명확하게 비교하기 위하여 소속 학과의 규모, 남녀 학생의 비율 등의 변인을 고려해 Q방법론을 적용할 수 있을 것이다(Hwang, Jung \& Lee, 2012).

셋째, 본 연구에서 도출된 세 유형에 소속된 학생들이 왜 특정한 관점을 지니게 되었는지에 대한 분석을 하지 못했다(Cho, 2016). 향후 연구에서는 이러한 점을 보완 할 수 있는 연구 설계가 진행되어야 할 것이다.

\section{참고문헌}

Chang, Y. H., Lee, J. S., \& Sin, E. S. (2016). The relations between career barriers and career preparation behavior perceived by college students: The mediating effect of subjective happiness. The Journal of Educational Research, 14(2), 163-184.

Cho, K. C. (2016). An explorative study of perception on multicultural awareness of middle school students using Q methodology. Social Studies Education, 55(2), 141-152.

Chuang, N. (2010) The impact of gender on hospitality undergraduates' perceived career barriers. Journal of Hospitality \& Tourism Education, 22(3), 12-19.

Economist. (2019, Mar. 8). The glass-ceiling index. Economist. Retrieved from https://www.economist.com/graphic-detail/ 2019/03/08/the-glass-ceiling-index

Ha, J. Y., Kim, J. M., Kang, J. E., \& Cha, J. C. (2017). Analysis of the differences among core competency of collegiate and 
career preparation behavior, career decision-making self-efficacy, career barriers. The Journal of the Korea Contents Association, 17(5), 80-89.

Harris, K. F. H. F., Grappendorf, H., Aicher, T., \& Veraldo, C. (2015). "Discrimination? Low pay? Long hours? I am still excited:” Female sport management students' perceptions of barriers toward a future career in sport. Advancing Women in Leadership, 35, 12-21.

Hong, M. Y. (2004). An exploratory study on the 'glass-ceiling' for the senior woman public officials: The comparison of the perception by gender difference. Korean Society and Public Administration, 15(3), 329-363.

Huang, C. J., Chou, C. C., \& Hung, T. M. (2016). College experiences and career barriers among semi-professional student-athletes. Career Development International, 21(6), 571-586.

Hwang, H. J., Jung, H. Y., \& Lee, K. H. (2012). The Typology of Early Childhood Teachers` Belief on Multiculture by Q Methodology. Journal of Future Early Childhood Education, 19(4), 475-503.

Jo, M. H., \& Lee, J. Y. (2019, Jan. 12). 223 female athletes and 0 female coach, cause of sport sector 'me too'. Sisajournal. Retrieved from https://www.sisajournal.com/news/articleVie w.html?idxno=180003

Joo, J. M. (2010). Institutional plans for hiring of athletic coach by gender equity. The Journal of Sports and Entertainment Law, 13(3), 211-239.

Kang, H. H. (2015). Effect of career barrier on polytechnics students' career preparation behavior: The mediating effects of career resilience. The Journal of Career Education Research, 28(1), 59-78.

Kim, G. S., Kim, J. H., Choi, M. S., Park, J. G., \& Eom, D. Y. (2011). Astudy for developing and validating an instrument for testing physical education students' career barriers. The Korean Society of Sports Science, 20(4), 153-167.

Kim, H. J., \& Yoon, H. H. (2016). The influence of career barriers on college students majoring in culinary arts on career preparation behavior: The moderating effect of self-efficacy. Culinary Science and Hospitality Research, 22(4), 65-80.

Kim, H. K. (1992). Understanding and applying of Q methodology. Seoul: Sogang University Journalism \& Culture Institute.

Kim, H. K. (2008). Q methodology: Philosophy of science, theoty, analysis and application. Seoul: Communicationbooks.
Kim, J. U., \& Park, S. S. (2013). The mediating effects of career decision-making self-efficacy on the relationship between career barriers and career preparation behavior of college students. The Journal of Career Education Research, 26(3), 123-141.

Kim, J. H. (2009). Feminie gender roles, feminine gender role conflicts, decision-making-dependency and career decision in Korean female college students. Asian Journal of Education 10(3), 239-256.

Kim, M. H., \& Choi, W. Y. (2014). The influence of career barriers perceived by general female high school student, career decision-making self-efficacy, career outcome expectation on career preparation behavior: The mediating effects of career aspiration. The Journal of Career Education Research, 27(1), 83-107.

Kim, M. J. (2016). Effect of career barrier on college students' career preparation behavior: The mediating effect of career self-regulation. The Journal of Career Education Research, 29(2), 89-107.

Kim, M. J. (2018). Experience of glass ceiling by hospitality industry female employees: Aexploratory study based on grounded theory. Northeast Asia Tourism Research, 14(2), 111-131.

Kim, W. K. (2018). An exploration on university students' motivation types of participation to cultural physical education: Using Q-methodology. The Journal of LearnerCentered Curriculum and Instruction, 18(16), 85-105.

Kim, Y. M., \& Seo, S. J. (2016). Astudy on expanding measures of the increase of supply \& demand for the employment of professional sports woman. The Korean Journal of Physical Education, 55(3), 95-111.

Korean Society for the Science Study of Subjectivity. (2002). Subjectivity study. Seoul: Communicationbooks.

Korean Society for the Science Study of Subjectivity. (2014). Application and Case of Q methodology. Seoul: Prunsasang. KOSIS. (2014). Economically active population survey. http://kosis.kr

Lee, J. H., Han, Y. H., Sung, H. J., \& In, J. (2007). The glass ceiling in the Korean public service. Journal of Korean Women 's Studies, 23(3), 79-115.

Lee, S. J., \& Yu, J. H. (2009). A causal model among self-determination, career stress, career barriers, and career decision level of female college students in Korea. Journal of Asian Women, 48(2), 35-63.

Lee, S. S., \& Jyung, C. Y. (2007). A casual model among perceived 
career barriers, career decision-making self-efficacy, and career decision level of female college students. Journal of Agricultural Education and Human Resource Development, 39(4), 83-109.

Lee, S. Y. (2019, Jan. 17). The glass ceiling caused 'me too', only 1 in 10 female executives in sport sector. The Hankook Ilbo. Retrieved from https://www.hankookilbo.com/News/Read/20 1901171621043090 ?did=NA\&dtype $=\& d t y p e c o d e=\& p r n e w s i d=$

Lee, W. I., Lee, E. Y., Yi, K. J., \& Jin, Y. K. (2019) Systematic Review in Regard to Career Education for Students Who Major in Physical Education. The Korean Journal of Physical Education, 58(3), 241-260.

Lee, Y. G. (2016). Career preparing behaviors and exploration of measures for convergence talent education in college students of physical education and related department. Journal of Digital Convergence, 14(8), 487-496.

Lee, Y. K., Yang, K. J., \& Yoo, J. Y. (2020). The effects of in-school job experiences on accordance ratio between major and the first job among arts \& physical college students. The Journal of Employment and Career, 10(1), 79-99.

Lem, Y. S., \& An, Y. J. (2016). A qualitative study on how female university student explores the meaning of 'work as a woman'. The Korean Journal of Woman Psychology, 21(2), 173-206.

Lent, R. W., Brown, S. D., \& Hackett, G. (2002). Social cognitive career theory. Career Choice and Development, 4, 255-311.

Lim, J. S., \& Chang, I. O. (2015). A structural analysis among perceived career barriers, career certainty, and career preparation behavior of female junior college students. Journal of Future Oriented Youth Society, 12(1), 49-67.

Mau, W. (1995). Decision-making styles as a predictor of career decision status and treatment gains. Journal of Career Assessment, 3, 90-101.

Mau, W. (2000). Cultural differences in career decision making styles and self efficacy. Journal of Vocational Behavior, 57, 365-378.

McKeown, B., \& Thomas, D. B. (2013). Q methodology (Vol. 66). CA: Sage Publications.

Min, J. A. (2012). The effect of the glass ceiling on the organizational performance: Focused on moderating effect of different types of hospitality and tourism companies. Journal of Tourism and Leisure Research, 24(2), 119-135.

Ministry of Education. (2017, Dec. 14). 2017 Career Education Status of Universities. Sejong: Ministry of Education.
Moon, Y. L. (2020, Feb. 10). "I will gain job experience" $60 \%$ of university graduates, leave of absence and delay of graduation. The Chosun Ilbo. Retrieved from https://news.chosun.com/site /data/html_dir/2020/02/10/2020021003145.html?utm_source =naver\&utm_medium=original\&utm_campaign=news

Morrison, A. M., White, R. P., \& Van Velsor, E. (1987). Breaking the glass ceiling: Can women reach the top of america's largest corporations?. London: Pearson Education.

Nam, S. W. (2019). A conceptualization of sexism in sport organizations. Korean Journal of Physical Education, 58(2), 65-75.

Nam, S. W., \& Lee, H. R. (2019). Theorizing gender doing of female physical education teachers in culture of hyper-masculine physical education. Korean Society for the Sociology of Sport 32(1), 1-19.

Oh, C. S., \& Lee, B. H. (2005). Factors influencing career decision making in adolescents and female college students. Korean Journal of Youth Studies, 12(3), 93-113.

Oh, J. S. (2017). Gender inequality experienced among female sport coaches: A feminist perspective. Journal of Korean Association of Physical Education and Sport for Girls and Women, 31(2), 1-22.

Organization for Economic Cooperation and Development. (2017). OECD Employment outlook 2017. Paris: OECD Publishing.

Park, J. J., \& Hong, A. R. (2016). Direction of university career education through career perception of sports-related university students. Korean Association of Sport Pedagogy, 23(3), 65-88.

Park, J. Y. (2014). The role conflicts of the women workers in sport administrative organization. Unpublished doctoral dissertation. Chungnam National University.

Park, S. H., \& Ahn, J. H. (2016). A study on the difference of career barriers, career attitude maturity, and career competencies based on gender, grade, and fields of major of undergraduate students in the age of convergence. Journal of Digital Convergence, 14(8), 69-80.

Park, S. H., Shin, D. E., \& Choi, K. J. (2010). The differences of gender awareness on women engineers career barriers. Journal of Engineering Education Research, 13(4), 77-86.

Park, Y. O. (2018). A study on the effects of perceived career barrier by university students on their satisfaction with career education, career self-efficacy, and employment preparation behavior: Focusing on university students majoring in airline 
service. Journal of Employment and Career, 8(3), 81-107.

Phillips, S. D., Pazienza, N. J., \& Walshi, D. J. (1984). Decision making styles and progress in occupational decision making. Journal of Vocational Behavior, 25, 96-105.

Ryu, D. S., Park, M. S., \& Kim, J. K. (2014). The effect of education satisfaction and evaluation in the employment supporting program on employment barrier awareness level and career preparation behavior of sports related majoring university student. Korean Journal of Physical Education, 53(4), 293-305.

Ryu, J. E., \& Jeong, J. C. (2016). A study on the perception, regarding career barriers and the career compromise types of female college students in science \& engineering majors. The Journal of Career Education Research, 29(2), 145-166.

Son, H. S. (2015). A legal study on sports related legislation for gender equality. CHUNG-ANG LAWREVIEW, 17(2), 111-143.

Shin, J. H. (2015). An exploration of physical education major student"s employment apprehension factor. Korean Journal of Sports Science 24(5), 561-574.

Shon, E. R. (2001a). Career barriers perceived by female college students. Unpublished doctoral dissertation. Seoul National University.

Shon, E. R. (2001b). The relation of career barriers perceived by female college students and career decision. Korea Journal of Counseling, 2(2), 251-262.

Stephenson, W. (1953). The study of behavior: Q-technique and its methodology. IL: University of Chicago Press.

Urbanaviciute, I., Pociute, B., Kairys, A., \& Liniauskaite, A. (2016). Perceived career barriers and vocational outcomes among university undergraduates: Exploring mediation and moderation effects. Journal of Vocational Behavior, 92, 12-21.

Watts, L. L., Frame, M. C., Moffett, R. G., Van Hein, J. L., \& Hein, M. (2015). The relationship between gender, perceived career barriers, and occupational aspirations. Journal of Applied Social Psychology, 45(1), 10-22.

Watts, S., \& Stenner, P. (2005). Doing Q methodology: Theory, method and interpretation. Qualitative Research in Psychology, 2(1), 67-91.

Won, H. S. (2018, Mar. 15). 2018 Status preparation for public employment. Jobkorea. Retrieved from https://www.jobkorea. co.kr/goodjob/tip/View?News_No=14252\&schCtgr=101004

Wrigley, B. J. (2002). Glass ceiling? what glass ceiling? a qualitative study of how women view the glass ceiling in public relations and communications management. Journal of Public Relations Research, 14(1), 27-55.

\title{
체육계열 여자 대학생의 진로장벽에 관한 주관성 유형화
}

\author{
명왕성 ${ }^{1}$, 홍은아 ${ }^{2}$ \\ ${ }^{1}$ 연세대학교, 시간강사 \\ ${ }^{2}$ 이화여자대학교, 조교수
}

〔목적〕 본 연구는 체육계열 여자 대학생이 지각하는 진로장벽에 관한 심리적 주관성과 수용인식을 유형화 하는데 그 목적이 있다. 〔방법) 연구목적을 달성하기 위하여 Q방법론을 활용하였다. Q모집단 구성은 문헌고 찰과 심층면담, 개방형 질문지 등 다각적 자료수집방법을 활용하였으며 25개의 Q-표본을 선정하였다. 30 명 의 P-표본을 분석에 활용하였고 자료처리는 PQmethod 소프트웨어를 사용하였다. [결과) 연구 결과 세 유형 이 도출되었다. 첫째, 자신의 적성과 흥미를 아직 발견하지 못한 '진로 불확실형', 둘째, 희망 직업의 성차별적 요소를 인식한 ‘성차별-남성중심형', 셋째, 자신의 직업 관련 현장경험이나 자격 요건이 부족하다고 수용하는 ‘경험-자격 부족형'이다. 〔결론) 각 유형은 개인 내부(진로결정, 의사결정의존성)와 외부(법제도적 측면, 대학의 교육과정)에 존재하는 장벽으로 특징지어졌으며, 이를 바탕으로 진로교육 정책 수립의 필요성을 강조하였다.

주요어: 체육계열, 여자 대학생, 진로장벽, 주관성, $\mathrm{Q}$ 방법론 